\title{
Deseo y pecado: de la teología del error a la teología indecente
}

\section{Desire and Sin: From Theology of Error to Indecent Theology}

\author{
Gabriela González Ortuño \\ Facultad de Estudios Superiores Acatlán \\ Universidad Nacional Autónoma de México \\ gaby.ggo@gmail.com
}

Eric Martínez Tomasini-Bassols

Savitribai Phule Pune University

tomasini.bassols93@gmail.com

Resumen: En este artículo se entrecruzan miradas fenomenológicas y análisis discursivos dirigidos a transmutar al pecado desde el cuerpo hacia la estructura social, y pasar de ver el cuerpo como objeto de pecado a ser "lugar de liberación" en las teologías de liberación latinoamericanas afrofeministas e indecentes; en segunda instancia, se propone desde ahí explorar las diversas imbricaciones del pecado con el ejercicio de la sexualidad y la continencia de los placeres corporales, cuestiones que establecen los ordenamientos políticos modernos y sus tensiones a través de los vínculos entre estos temas y la antropología libertaria planteada por autores como Giorgio Agamben, quien coloca al deseo al centro de la cuestión política.

Palabras clave: pecado, deseo, teología política, teología de liberación

Abstract: This article results from the interplay of phenomenological approaches and discourse analysis aimed at transmuting sin from the body to social structure, and shifting the body from a place of sin to a "place of liberation"; secondly, it seeks to explore the many relations of sin with sexuality and the restriction of bodily pleasures, issues that establish modern political order and tensions. At last, the connections between these subjects and the libertarian anthropology of authors such as Giorgio Agamben, who places desire at the center of the political question, are reviewed.

Keywords: $\quad$ sin, desire, political theology, liberation theology 
Recibido: $\quad 25$ de septiembre de 2018

Aceptado: $\quad 22$ de octubre de 2018

Y fue tan cuerpo que fue puro espíritu.

Cerca del corazón salvaje, CLARICE LISPECTOR

El cristianismo, desde su surgimiento, define la salvación como fin último: el reino de Dios, su advenimiento, la posibilidad de vida eterna son los móviles de la organización de millones de personas alrededor del mundo hoy y de cientos de millones a lo largo de la historia. Esto ha tenido como consecuencias políticas y económicas las imposiciones coloniales o disputas religiosas que han derivado en guerras intestinas por el dominio territorial. Simultáneamente, la idea de salvación ha servido para elaborar formas de liberación: esclavos que huyen de sus amos, comunidades que se levantan contra sus opresores porque tienen a "Dios" de su lado, y, en menor medida, organizaciones comunitarias que resisten embates de valores que no consideran cristianos, como la avaricia y la explotación. Son múltiples las posiciones desde las que se ha comprendido y vivido el cristianismo, aunque en todas ellas hay un concepto de falta, de falla, que ha servido para marcar sus límites de pertenencia/exclusión: el pecado.

\section{De la falta a la culpa, o de cómo disciplinar disidencias}

La idea de pecado refiere etimológicamente a un tropiezo; a partir de allí, llegó a referir el alejamiento del ser humano y lo divino a través de un yerro, ${ }^{1}$ toda vez que su uso político remite a algo que se concibe como peligroso, monstruoso, algo que no encaja en el orden impuesto y, por tanto, debe ser castigado o suprimido. Es por esa razón que podemos decir que el pecado no ha sido construido siempre sobre los mismos parámetros, ya que responde a coyunturas histórico-políticas específicas. Comparándolo con su acepción general de falta o yerro, nos hallamos frente a un significante que, aunque anclado en la idea de mal, mantiene el carácter relacional del significado (Laclau y Mouffe 2004). Así lo ha dicho Omar Abboud: "El pecado no es algo inamovible. Varía de acuerdo con el punto de vista del observador y en referencia a la evolución del contexto social y cultural. La mayoría de las acciones consideradas

1 En latín peccatum, en griego hamartía, en hebreo jattáth. Agradecemos a Camila Joselevich por su aclaración sobre esta etimología. 
como pecado hace dos siglos - un periodo ínfimo en la historia de la humanidad - hoy no tienen entidad pecaminosa" (Abboud citado en Savater 2005: 14). Y no solo eso, el carácter relacional del pecado inaugura la desigualdad en dichas relaciones al incorporar ideas de jerarquía que traen inscritas vergüenzas públicas para aquel que peca, castigo humano e institucional a quien lo comete. No se trata únicamente de una forma de culpa frente a la divinidad; las consecuencias del pecado son sociales y, en algunos casos, materiales. Las subjetividades y los cuerpos que encarnan la falta han sido formados en muchas ocasiones por ella, por su evasión, su práctica o su punición mediante los dispositivos que lo rodean: la confesión, la penitencia y el perdón.

El pecado es primero y, antes que nada, falta de amor, y así queda definido en la tradición católica: "El pecado es una falta contra la razón, la verdad, la conciencia recta; es faltar al amor verdadero para con Dios y para con el prójimo, a causa de un apego perverso a ciertos bienes. Hiere la naturaleza del hombre y atenta contra la solidaridad humana" (Coeditores Católicos de México s/a: 508). No obstante, como resalta Juan Esteban Londoño, el pecado original, su origen edénico, y la relación que este adquiere con el cuerpo y la sexualidad, se construyen a partir de san Agustín, pues hasta entonces no resultaba claro de qué modos específicos el distanciamiento de los primeros humanos en el Génesis, su caída "fundacional", hallaba su expresión directa en los cuerpos (Londoño 2018: 168-182). La conversión y la subsecuente interpretación hermenéutica que hace san Agustín tanto del Génesis como de los textos paulinos son piedras angulares en nuestra genealogía del pecado. En efecto, el pensador de Hipona transformó los conceptos de pecado y caída para adecuarlos tanto a sus proyectos de redención personal como a sus empresas teóricas, con lo cual, según Hans Küng, se "intensifica la idea de miseria humana y del mundo mediante la historización, psicologización y sobre todo sexualización del pecado original" (1995: 83).

Agustín supone que la condición de los hijos de Adán es cargar con el recuerdo del primer alejamiento esencial del ser humano con Dios: al ser expulsados del Edén, Adán y Eva son devueltos por primera vez a su irreversible desnudez, símbolo de una conciencia que remite a una traición y por lo tanto a una falta de amor hacia Dios. Adán escogió rechazar el Edén por amor a Eva, y ella, por concupiscencia, lo sedujo al momento de hacerle descubrir su propia desnudez. La revelación de la desnudez, y por tanto la conciencia de que se posee la capacidad de desear al otro con lujuria y placer, es la causa motora de una caída estrepitosa de la cual la humanidad no se ha recuperado, 
ni siquiera con la venida de Cristo, pues Jesús fue concebido sin coito y por ende sin pecado.

Así, el sexo queda definitivamente identificado con el pecado, como sinónimos; y es preciso mencionar que esta ecuación agustiniana se desprende tanto de su motivación personal por una redención para su propia vida -en la cual hallamos todo tipo de experiencias sensuales e ilícitos, como la relación incestuosa con su madre tras el abandono de su primera amante-, así como de la voluntad de hacer concretas las dimensiones metafóricas del Antiguo Testamento y justificar con argumentos supuestamente históricos la mancha del pecado original que todos portamos y repetimos cada vez que dejamos libre curso a los deseos de la piel.

En la medida en que el pecado se ata al cuerpo y sus necesidades, también la penitencia y la redención lo hacen: el catecismo anuda el pecado a la confesión y a la penitencia. Esta última se concibe como un acto de arrepentimiento y reparación que podría considerarse una forma de materializar el arrepentimiento por cometer la falta; sin embargo, se convierte en una herramienta para someter a los cuerpos a formas disciplinarias como autoflagelos, la carga de zarzas en la espalda o el ayuno, entre otros castigos penitenciales. También las limosnas a las iglesias han sido usadas como forma de "reparación" por los pecados, de tal suerte que las disposiciones eclesiales en torno al pecado no se ubican únicamente dentro de un plano espiritual: al condenar excesos o formas de relacionarse, configuran comportamientos sociales.

Bataille (2005) destaca al pensar en el pecado desde la filosofía anudándolo al deseo y a la idea de cima moral, la cual podría concebirse como la fijación lacaniana del neurótico con el cumplimiento de la ley. La relación pecado/ ley también es trascendente en el debate en torno a la forma como el pecado opera, ya que para mantener su fuerza es necesaria la punición a través de instituciones establecidas que tengan preceptos legales que delimiten el actuar de los fieles. ${ }^{2}$

Con esto se apunta a una lectura teopolítica de la función de la prohibición. Aquel que se encuentra en falta conoce de ella por su inscripción en la legislación, mientras que quien tiene fe ni siquiera necesitaría de ella porque

2 Esta relación ha sido estudiada también por Franz Hinkelammert en su lectura de Pablo de Tarso en Las armas ideológicas de la muerte. Ahí afirma: “Todo lo que causa muerte es pecado... El pecado es un fetiche que vive por la ley" (Hinkelammert 1978: s/p). 
sus actos son conducidos con amor. ${ }^{3}$ Sin embargo, esto no basta para la institución eclesial. El solo acto de reconocer y solicitar misericordia divina no es suficiente para las iglesias; la falta en la religión cristiana católica precisa de penitencia y en muchas otras variantes cristianas es necesario confesar públicamente o a un pequeño grupo de sacerdotes, pastores o ancianos, el pecado cometido. Se trata de una práctica en la que la relación religadora precisa de una mediación, de un escarnio público. Así, tanto el pecado como la penitencia estarían atados al cuerpo mientras la confesión se construye como un acto público, una forma de control político.

La dimensión político-moral del pecado aparece en Europa como un contrapunto a las formas propias de la Antigüedad de vincular las prácticas sexuales con la vida moral de los individuos. Antes del cristianismo, en la cultura grecorromana, la visión de los antiguos a propósito del sexo y las relaciones amorosas se integraba perfectamente con la noción que sostenían a propósito de la virtud y de la vida ética, tanto en los asuntos privados como en los públicos. En otras palabras, el deseo carnal y la relación amorosa no eran juzgados en sí mismos sino siempre en relación con una aspiración hacia la virtud. En ningún caso, por ejemplo, se pensaba en evaluar la calidad moral de un individuo griego por sus prácticas eróticas como tales, fuesen estas afines a lo que hoy llamaríamos "homosexuales", "adúlteras" o meramente conducidas por el goce sensual, sino que se hacía análisis en situación, determinando qué tanto el individuo y sus prácticas se ajustaban a la ciudad y sus imperativos de virtud. La cercanía con la areté y la aspiración hacia la sabiduría implicada en la práctica amorosa eran más importantes para los griegos que el control de los cuerpos y su dominio. El cristianismo sería, pues, desde estas consideraciones, el que habría inaugurado el biopoder instalando en el territorio del cuerpo manchado por el pecado -y por lo tanto salvable- los mecanismos de un control sin precedentes.

En ese sentido, Michel Foucault (2012) nos habla de la relación de poder del pecado, administrado a través de la confesión, ${ }^{4}$ práctica que otorga autoridad al que "sabe" acerca del otro; en este caso, no se trataría únicamente de un saber cualquiera sobre el otro, sino de un saber sobre su pecado, su falta,

3 A esto mismo se apunta con las lecturas de otros pasajes bíblicos, como el sacrificio que pide Dios a Abraham y que es analizado por Derrida a la luz del deber ser frente a la ley en Dar la muerte (2006).

4 Dicha práctica se extendería en instituciones laicas, como la ciencia médica y la pedagogía. 
su traición a la fe que dice profesar y, por tanto, su traición a la comunidad con la que comparte aquello tan íntimo como es su relación con lo divino. Aunque el francés encamina la práctica de la confesión al ejercicio de la sexualidad, es posible ver cómo, a través del dispositivo "pecado", las fronteras no solo religiosas sino sociales se constituyen. ${ }^{5} \mathrm{El}$ pecado, inicialmente comprendido como una falta, un yerro en el camino de la salvación, tomó posteriormente forma de un discurso maniqueo de bondad/maldad que sirvió de herramienta al disciplinamiento de comunidades enteras. ${ }^{6}$

Si retomamos a Hinkelammert y su apego a Pablo en la negación de la ley como medio de salvación, encontramos que el liberacionista también cree en la salvación de la carne, es decir, que el alma no es lo único en juego en las discusiones en torno al pecado, considerado por él como lo que da la muerte. ${ }^{7}$ Esto es importante porque, al analizar la diversidad de pecados, podemos encontrar que la mayor parte de ellos se enfoca a limitar las concupiscencias corpóreas. Si para santo Tomás el pecado es todo aquello que lleva al vicio, para el catecismo los pecados responden a las obras de la carne, y "las obras de la carne son conocidas: fornicación, impureza, libertinaje, idolatría, hechicería, odios, discordia, celos, iras, rencillas, divisiones, disensiones, envidias, embriagueces, orgías y cosas semejantes" (Gal 5:19-21, en Coeditores Católicos de México s/a: 509).

El cuerpo y sus necesidades han sido el objeto favorito de castigo y disciplinamiento. Silvia Federici (2004) nos recuerda que entre las acusaciones de brujería destacaban las que tenían que ver con orgías y grandes banquetes en el aquelarre, cuestiones mal vistas debido a los excesos que no podían (ni debían) cometer las clases bajas en tiempos de hambruna. Aunque no podemos negar que tal vez en sus inicios la cada vez más precisa división de pecados hubiese podido corresponder a un orden de vida apostólico, de moderación y contemplación, es posible observar cómo han servido como dispositivos de

5 Un ejemplo de eso es la disputa de Las Casas-Sepúlveda, en la que se debatía acerca de si los indios eran pecadores por no tener alma o por su ignorancia.

6 Silvia Federici (2004), a través de la caza de brujas, señala cómo las acusaciones basadas en la idea de pecado - es decir, lo correcto/incorrecto- ayudó a disciplinar a comunidades europeas enteras, sobre todo a mujeres, de la misma forma que se hizo con los individuos de las comunidades colonizadas al ser acusados de ser diabólicos, de practicar rituales que caerían en falta para la religión colonial y que serviría también para calmar revueltas.

7 Para Hinkelammert, lo que causa la muerte es también el sistema capitalista de opresión que fetichiza el deseo de dominar al otro. 
control; el cuerpo se encuentra desde entonces en tensión con los mandatos de control sobre quien pretende ejercer una forma de fe cristiana. Lo que esto implica es un ordenamiento social de las relaciones, es decir, la conformación de un orden político.

Es posible afirmar, en este sentido, que si el pecado ha sostenido un papel simbólico tan grande en la conformación de las estructuras biopolíticas de Occidente es porque se relaciona, como las dos caras de Jano, con una pieza clave de estas mismas estructuras: el deseo. En efecto, desear - en su sentido más amplio, como aquello que Spinoza denominó el conatus, la voluntad propia de todos los seres de perseverar en el Ser- es algo tan propiamente humano que abarca toda dimensión, incluida la política. Una lectura libertaria de la historia de nuestra civilización, en la ruta filosófica de autores como La Boétie y Rousseau, diría — sin concluir de una vez por todas- que hemos sido más propensos a desear el dominio que la libertad; $y$ ambas posibilidades están contenidas, diríase, en el arché mismo que hace posible lo político, la vida en común, la vida compartida; pero, en apariencia, nos hemos acostumbrado a desear el dominio porque creemos falsamente que no hay otra cosa.

Ciertamente, buena parte de la tradición política en Occidente se sustenta en la creencia de que no existe otra posibilidad más que el dominio con el sistema de premios y castigos que ello implica; llámese entonces monarquía, dictadura del proletariado, totalitarismo, e incluso la "democracia" misma, en los hechos - no en la teoría-, subyace la noción de que algunos mandan - escriben las leyes, las hacen valer, se colocan fuera y dentro de ellas, como el soberano hobbesiano, que es simultáneamente fuente de autoridad y está sometido a ella- y otros obedecen. Aceptamos esta versión de las cosas porque no creemos que exista otra, porque lo hemos olvidado o porque no nos conviene que sea así, ya sea que por comodidad aceptemos los placeres de la servidumbre o que, por el poder que nos confiere el control sobre otros, no aceptemos nunca abandonar nuestra posición de mando, los privilegios de ser soberanos.

Una forma de instalar el dominio es abrazar la dicotomía castigar/ser castigado que una noción como la del pecado supone: ¿será entonces posible que internalicemos el pecado porque hallamos en él un deseo de ser sometidos y por lo tanto de ser reformados y liberados para siempre del deseo? Si el pecado es tan efectivo como mecanismo de control se debe quizá al hecho de que esconde un anhelo profundo de redención, el mismo anhelo que ani- 
maba a san Agustín al momento de condenar a los hombres a las injusticias de la vida en la Tierra, a la espera de un renacer sin manchas en la Ciudad de Dios. El deseo de dominar y ser dominado alcanza entonces su máximo grado de materialidad cuando el pecado nos convierte en cuerpos manchados por la culpa que pueden ser limpiados, salvados, devueltos a la pureza que los primeros hombres conocían antes de ser conscientes de su desnudez.

En la genealogía del pecado encontramos la raíz del deseo y la relación ambigua que el cristianismo sostiene con él; solo así pueden comprenderse las palabras de Giorgio Agamben cuando dice, en Profanaciones, que

el Mesías viene por nuestros deseos. Él los separa de las imágenes para cumplirlos. O, sobre todo, para mostrarlos ya realizados. Aquello que hemos imaginado, lo hemos obtenido ya. Permanecen — sin ser realizadas- las imágenes de lo cumplido. Con los deseos cumplidos, él construye el infierno; con las imágenes no realizadas, el limbo. Y con el deseo imaginado, con la pura palabra, la felicidad del paraíso (Agamben 2005: 68).

\section{Otra(s) teología(s): más allá del pecado}

Al hablar del pecado como una forma sistemática y estructural de perpetuar las injusticias, los teólogos de la liberación de primera generación desplazan los pecados de la carne. ${ }^{8}$ No es el cuerpo y sus necesidades el principal enemigo, sino quienes privan a este de lo necesario para una vida digna. ${ }^{9}$ La desvinculación carne-pecado y la lectura sociohistórica de las faltas hacen que estas recaigan en comunidades completas y, por tanto, la responsabilidad de reparar las faltas va mucho más allá de una simple penitencia. Esto no libra de la responsabilidad personal ya que, al igual que su contraparte conservadora, tienen sustento bíblico.

Desde la teología de la liberación, la confrontación con el mal se encuentra en las condiciones de opresión y el orden económico de explotación y de-

8 El desplazamiento del pecado a pecados estructurales, sociales o históricos también abre la puerta a interpretaciones como las de James Alison y la expiación, quien dice que el pecado se había desviado a la vigilancia de las conductas sexuales, sobre lo que basará su teoría de la expiación, enfocada a personas homosexuales (Alison 2008).

9 Nos apegamos a la idea de León Olivé según la cual una vida digna es aquella que permite a un ser humano realizar su plan de vida siempre y cuando este no dañe a otros (Olivé 2004). 
pendencia, por lo que el pecado se encontrará inscrito contra el despojo de quienes menos tienen. Los liberacionistas toman partido por el sector menos favorecido por el modelo moderno liberal capitalista, por lo que Mo Sung afirma: "El lugar por excelencia en el que podemos experimentar la experiencia de Dios en la historia y al mismo tiempo criticar radicalmente la idolatría del mercado es en medio de los pobres, los excluidos del sistema que se absolutiza" (Mo Sung 1999: 177). Por otro lado, las teologías posliberacionistas son teologías que, aunque se reconocen herederas de la teología de la liberación, han cuestionado su lugar de interpretación hermenéutica y también, en algunas ocasiones sin proponérselo, en otras de forma más clara, han reubicado al pecado y reivindicado el quehacer político del deseo y la sexualidad. En este caso, hablaremos de las teologías feministas negra e indecente.

Debemos comenzar por decir que, en general, las teologías feministas siguen la línea del pecado social, es decir, ponen un acento en el pecado como opresión contra otras, aunque su trabajo específico toma como lugar hermenéutico las situaciones específicas de las mujeres pobres y racializadas. De tal manera, sus visiones comienzan a ser distintas a la de sus pares varones en tanto empiezan a abordar temas que antes no habían sido considerados ni en la idea de religación a lo divino ni en la de liberación del pueblo de Dios. Así, encontramos a mujeres como la brasileña Ivone Gebara, quien habla del derecho a decidir de las mujeres - lo que le costó un año de silencio como castigo por parte de la Iglesia católica-, o la argentina Marcella AlthausReid, quien buscó desatar los ejercicios de la sexualidad de la idea de pecado en su teología, bautizada como "indecente" (Althaus-Reid 2005).

Para las teologías afro e indecente de liberación, las interpretaciones teológicas de religación son sensuales y sexuales. Debemos recordar que no todos los cuerpos fueron construidos como iguales desde la mirada occidental: a las poblaciones afro les fue atada la idea de la maldad, de lo diabólico, debido a su tono de piel. Las mujeres negras, en específico, fueron caracterizadas como hipersexuales y como brujas por usar sus conocimientos ancestrales para la curación. Sus religiones fueron ligadas a lo demoniaco y sus rituales a la posesión, por lo que pasaron a la clandestinidad o, en el mejor de los casos, lograron pasar por un proceso de sincretismo. En esta construcción podemos ver que el pecado se concibió como inserto en las almas y los cuerpos de seres considerados semihumanos: las personas esclavizadas. El amor al prójimo no se aplicaba a estas poblaciones: el pecado se encontraba en lo profundo de su ser, que fue bestializado para no reconocer los abusos sobre ellas. 
La construcción de pecado alrededor del cuerpo afro constituyó un dispositivo de poder que se ejerció sobre la construcción de subjetividades para subalternizarlas. Al construir a los cuerpos negros como hipersexuales y, por tanto, pecaminosos; al igualar sus creencias con la maldad, con el demonio; las poblaciones afrodescendientes se dibujaron como unas que se encuentran fuera de la divinidad, no fueron consideradas como parte del pueblo de Dios: ellas no estaban creadas a imagen y semejanza de Dios, lo cual constituye un claro ejemplo de cómo la idea de pecado excluyó a comunidades enteras como sujetos de vejación.

Así, hoy en día, teólogas feministas afrocristianas como Maricel Mena, a quien abordaremos a profundidad, buscan recuperar elementos de las religiosidades ancestrales y, a la vez, reivindicar sus cuerpos como lugares hermenéuticos. Los cuerpos antes violentados sexualmente, explotados laboralmente y tachados como pecadores, esta vez serán considerados parte de la divinidad, el lugar de conexión entre las mujeres y Dios. Las teólogas feministas afro no han escapado de la influencia de las principales pensadoras feministas afronorteamericanas, como Audre Lorde y su defensa de lo erótico como una fuerza femenina. La misma Mena ha hablado de las diversas influencias que ha tenido la teología afrofeminista que se desarrolla en la actualidad y que va desde la Black Theology hasta la Teología Womanista, las cuales buscan separarse de las feministas blancas (Mena 2014).

Para esta teología, la liberación se debe dar para las comunidades, pero también se debe dar desde una especie de empoderamiento de los cuerpos (Da Lima 2011), sobre todo de las mujeres afro, no de la forma hipersexualizada en que se los construyó, pero sí desde el punto de vista de un sujeto de experiencia y conocimientos, de praxis liberadoras de las que han formado parte. También para la teóloga Silvia Regina Da Lima Silva el pecado proviene de la explotación que han sufrido sus pueblos y de la violencia padecida por sus mujeres, del racismo y la colonialidad que persisten, no de las espiritualidades ancestrales; la maldad viene de los procesos de esclavitud y de las estructuras racistas y patriarcales. De este modo, las teólogas negras como Mena o Da Lima buscan desmontar los elementos a través de los cuales fueron consideradas pecadoras: su cuerpo, su tradición oral, el rescate de las mujeres africanas -y por tanto negras - de la Biblia y, de forma muy importante, elementos de las religiosidades ancestrales por los que fueron consideradas demoniacas. Mena, por ejemplo, trata de pensar al cristianismo a partir de las formas en que se imbricó con los "santos" africanos, lo que coloca estas formas de cristia- 
nismo fuera de las lógicas que tildaban de maldad a los elementos africanos. De esta forma, la idea de pecado se va a modificar hacia una violencia contra lo divino, en la cual los pueblos afro están insertos y que también abarca otros elementos: "La vida y la muerte son de origen divino. Por eso se condena cualquier violencia contra la vida humana. Si se rechaza la mediación, se pone en peligro la armonía, la paz, la solidaridad entre todos los seres creados. La mediación es relacional, pues en la espiritualidad afro hay una interrelación entre todos los seres y quien mejor ayuda en ese proceso es la madre" (Mena 2012: 186). A diferencia del patriarcado cristiano moderno, es alto el valor que se otorga a todos los seres humanos, a la naturaleza y a las mujeres.

\section{La teología indecente}

A partir de la que denominó "teología indecente de liberación latinoamericana”, Marcella Althaus-Reid, junto con algunos de sus continuadores identificados como teólogos queer, sostienen que no existe teología sin postura sexual y esto, para nosotros, trae una necesaria implicación política en tanto resulta un marcador de comportamiento social de las personas que profesan una fe y que son parte de organizaciones religiosas que tienen cada vez más incidencia en la política electoral. Para Althaus-Reid, el 'clóset' de la teología consiste en tratar de aparentar que la sexualidad y la construcción genérica es un acto neutral y que responde a mandatos divinos. Esto se hará a la par de un análisis de situación de clase, aunque no ahondará en la cuestión racial. Sin embargo, esta teología será una de las primeras en denunciar las condiciones coloniales o neocoloniales que aquejan a América Latina.

Esta teología tiene como antecedentes no solo a la teología de liberación latinoamericana sino a las teologías gay y lesbiana norteamericanas, las cuales han hecho énfasis en desatar pecado y sexualidad. Las teologías gay y lesbiana, desde posiciones liberales, han buscado mostrar la "bondad" de las personas homosexuales y demostrar asimismo que pueden ser cristianos capaces de vivir según las normas de la decencia, la monogamia y la fidelidad, en contraposición a la imagen de promiscuidad. Es decir, han adoptado posturas sexuales y políticas más cercanas a las ideas de Tomás de Aquino. Posteriormente, habrá otras propuestas que retomen lo erótico — teologías eróticas, según Elizabeth Stuart (2005) - como un vínculo con la divinidad. A diferencia de sus antecesoras liberales más conservadoras, aquellas se vinculan a la teología de la liberación y se consideran a sí mismas como el lugar de interpretación 
de un pueblo en éxodo. En esta línea, por ejemplo, encontramos a Michael Clark, quien desarrolla un vínculo con el ecofeminismo del cual trasladará la idea de pecado a la explotación irracional de la madre Tierra.

El problema del pecado en las primeras teologías de disidencia sexual se centró en el cuerpo y la sexualidad ante la aparición del VIH, que viró la atención de sus teólogas a temas como la resurrección e implicó un replanteamiento de la forma como se relacionaban las y los disidentes sexuales con otros, por lo que la ética sexual comenzó a desarrollarse a través de la idea de amistad. Esto implicó una propuesta de relaciones interpersonales y sexuales a través de la responsabilidad para con el/la otro/a. Así, el pecado radicaría en el no cuidado del otro, lo que no es meramente individual porque se inscribe dentro de una relación - aunque tampoco apela a lo estructural o a lo histórico-.

De esta forma, tanto en teología como en filosofía, el deseo y la sexualidad, después del golpe de muerte que aconteció con el VIH, retomaron parte de las premisas pretomasianas respecto a las relaciones amorosas, la idea de pecado y el cuidado. El ejemplo más claro de esto es Foucault y su historia de la sexualidad, aunque, desde la teología, la vertiente "indecente" latinoamericana de Althaus-Reid nos confrontó con la idea de un amor sin límites, no solo en lo referente a la sexualidad sino a las labores de cuidado de los otros. Esta teología es una teología sensual que apela al cuerpo, a la sexualidad y a las prácticas de religiosidad popular, que no se mantiene dentro de los límites de lo dictado por las instituciones religiosas para pensar lo erótico y la divinidad.

Esto le traerá importantes cuestionamientos desde las lógicas tradicionales de hacer teología. Desde el sadomasoquismo hasta el ejercicio de penitencias, el cuerpo aparece como el lugar de la divinidad donde el deseo, tan claro entre las místicas, se oculta o se vela a través de la penitencia en las iglesias cristianas. Por medio de ejemplos cotidianos y del testimonio propio, la teología indecente de liberación inicialmente busca intersecar lo sexual con la clase y su relación con lo divino, ya que el hacer teológico es un quehacer sexual y político.

La teología indecente de liberación busca desestabilizar la manera en que se ha construido la fe apelando al amor, a la solidaridad a través de un concepto que resulta clave desde el desarrollo de las teologías gay y lesbiana: la amistad. Así, además de continuar con la línea de las teologías feministas que desvinculan al cuerpo del pecado, esta vertiente desplaza también a la 
sexualidad como uno de los lugares donde el pecado se ubica. La posición de la sexualidad para la teología indecente o queer será una forma de acercarse al prójimo y, por tanto, a la divinidad, aunque todo el tiempo hará alusión a las cuestiones de clase, de raza e, incluso, a dinámicas coloniales o neocoloniales de establecer la jerarquía eclesial y las trabas en el ejercicio de la fe. Para la teología indecente o queer, lo importante será encontrar formas perversas de acercarse a Dios, es decir, vías distintas a las tradicionales que retomen posicionamientos sexuales considerados políticos en tanto que organizan a las estructuras eclesiales, es decir, estructuras de fe, a quienes se les permite o se les vedan determinadas formas de uso del propio cuerpo.

La teología queer o teología indecente estará cercana a la idea de pecado social de la primera teología de la liberación. Sin embargo, este no se encontrará únicamente en las condiciones de explotación económica, sino en otras formas de opresión como la sexualidad, el racismo y el proceso de neocolonialidad llevado a cabo por Estados Unidos, aunque no se alejará de las consecuencias sobre las subjetividades de las y los creyentes. Al igual que la teología feminista afro, la teología indecente se enfocará en las opresiones interseccionales para construir su idea de pecado. Este no se encuentra en el apego al binomio genérico ni a las prácticas sexuales disidentes: es un reto a la idea del pecado desde el cuerpo hipersexuado de la negra y del deseo que construyeron como sodomita, todo lo cual sirvió de marcador para el pecado y la construcción de subjetividades subalternas colonizadas.

Lo verdaderamente interesante de estas propuestas, desde el punto de vista filosófico, es que nos reúnen con nuestro propio cuerpo como el sitio de algo que no es solo carne ni desnudez primigenia; es decir, nos sugieren la posibilidad de una liberación que no consiste en desprendernos del deseo ni de la humanidad, sino en acercarnos a ellos y sentirlos más profundamente. Si el impulso del primer cristianismo fue condenar a los humanos al pecado en esta vida para trascender lo humano y tocar lo divino en la siguiente, lo que anima a las nuevas teologías de la liberación es la trascendencia en la inmanencia que reivindica lo sagrado en lo humano mismo, en la raíz misma de su humanidad.

\section{Consideraciones finales}

El pecado se ha transformado a lo largo de la historia del cristianismo, desde su primera acepción como yerro y alejamiento, hasta la transfiguración de 
san Agustín en una culpa y una vergüenza materializadas en cuerpos y subjetividades pecaminosas, cuyo fin disciplinar es posible gracias a dispositivos físicos y espirituales varios. Esto ocurre, quizá, porque la noción de pecado se entrevera con el deseo de dominar/ser dominados, salvar y ser salvados, y con las lógicas consecuentes que el propio deseo impone.

La tensión entre el pecado, que nos confina irremediablemente a la individualidad, y su liberación, el establecimiento de relaciones amorosas, sexuales y políticas más allá de la dominación, es lo que se juega en el capitalismo y es el reto que hay que vencer hoy que la mercantilización ha alcanzado niveles impensados tanto en lo emocional como en lo espiritual. La liberación consiste primero en vernos, en hacer conciencia de que somos cuerpo y deseo, $y$, en segundo lugar, en la noción de que el cuerpo puede dirigirse también al amor; que hay espacio para algo como el cuidado y la aceptación plena del mundo. Desear la libertad es una posibilidad tan grande y tan presente como desear el dominio; y es precisamente el punto en el que nos reconocemos capaces de desear también la libertad, para nosotros mismos y para los demás.

\section{Referencias bibliográficas}

Agamben, Giorgio (2005). Profanaciones. Buenos Aires, Adriana Hidalgo Editora.

Alison, James (2008). Para la libertad nos ha liberado: acercamientos para desatar los nudos de la expiación y la conciencia gay. Guadalajara, Instituto Tecnológico y de Estudios Superiores de Occidente.

Althaus-Reid, Marcella (2005). La teología indecente. Pervesiones teológicas en sexo, género y política. Barcelona, Bella Terra.

Bataille, Georges et al. (2005). Discusión sobre el pecado. Buenos Aires, Editorial Paraíso.

Coeditores Católicos de México (s/a). Catecismo de la Iglesia católica. México, Coeditores Católicos de México.

DerRIDA, Jacques (2006). Dar la muerte. Barcelona, Paidós.

FEDERICI, Silvia (2004). Calibán y la bruja. Mujeres, cuerpo y acumulación originaria. Madrid, Traficantes de sueños.

Foucault, Michel (2012). Historia de la sexualidad. I. La voluntad del saber. México, Siglo XXI.

HinKelammert, Franz (1978). Las armas ideológicas de la muerte. Salamanca, Sígueme.

KüNG, Hans (1995). Grandes pensadores cristianos. Madrid, Trotta.

LAClAU, Ernesto, y Chantal Mouffe (2004). Hegemonía y estrategia socialista. Hacia una radicalización de la democracia. Buenos Aires, Fondo de Cultura Económica. 
LoNDOÑo, Juan Esteban (2018). “Génesis 3: sabiduría y mito”, en Perseitas, 6 (1): 168182.

MENA, Maricel (2012). "Espiritualidad mariana y diáspora afrocolombiana”, en Albertus Magnus, 4 (2), julio-diciembre: 179-195.

Mena, Maricel (2014). “Teología Negra de Liberación: apuntes a propósito de los 50 años del Concilio Vaticano Segundo", en Alberto Magnus: 87-106.

Mo Sung, Jung (1999). Deseo, mercado, religión. México, Ediciones Dabar.

OLIVÉ, León (2004). Interculturalismo y justicia social. México, Universidad Nacional Autónoma de México.

SAVATER, Fernando (2005). Los siete pecados capitales. México, Debate.

\section{Gabriela González Ortuño}

Doctora en Estudios Latinoamericanos por la Universidad Nacional Autónoma de México. Editora académica de la antología Mujeres intelectuales: feminismos y liberación en América Latina y el Caribe (CLACSO, 2017). Es autora de "(Trans) Modernidad y feminismo en dos pensadoras caribeñas contemporáneas: Ochy Curiel y Yuderkys Espinosa”, en José Gandarilla (coord.). La crítica en el margen. Hacia una cartografía conceptual para rediscutir la modernidad (Akal, 2016) y "Del dolor a la disidencia en la expresión neobarrosa de Néstor Perlongher", en León Barrón y Víctor Pacheco. Confluencias barrocas. Los pliegues de la modernidad en América Latina (Almenara, 2017), entre otros artículos.

\section{Eric Martínez Tomasini-Bassols}

Licenciado en Ciencia Política por el Instituto Técnológico Autónomo de México con la tesis El tiempo del Mesías: una investigación sobre las raíces teológicas del Estado moderno. Estudia la maestría en Filosofía en la Savitribai Phule Pune University en Pune, India. Fue miembro del consejo editorial de la revista Opción ITAM. 